Научная статья

УДК 338.242

DOI 10.18101/2304-4446-2021-4-10-17

\title{
УПРАВЛЕНИЕ СОЦИАЛЬНО-ЭКОНОМИЧЕСКИМИ СИСТЕМАМИ В УСЛОВИЯХ РОСТА НЕОПРЕДЕЛЕННОСТИ И НОВЫХ СОЦИАЛЬНЫХ ВЫЗОВОВ
}

\author{
(C) Афонасова Маргарита Алексеевна \\ доктор экономических наук, профессор, \\ Томский государственный университет систем управления и радиоэлектроники \\ Россия, 634050, г. Томск, пр. Ленина, 40 \\ afonasova@yandex.ru
}

\begin{abstract}
Аннотация. В статье рассматриваются методологические аспекты управления социально-экономическими системами в периоды масштабных изменений и трансформаций, обусловленных новыми технологическими, экономическими и социальными вызовами. Актуальность исследования обусловлена отсутствием общепризнанной научно обоснованной методологии государственного управления развитием социальноэкономических систем, функционирующих в режимах с обострением, спровоцированных новыми вызовами и угрозами, ростом неустойчивости и непредсказуемости внешней среды. В статье раскрываются особенности функционирования систем в режиме с обострением и направления управляющих воздействий на систему в моменты обострения. В работе рассмотрены механизмы управления социально-экономическими системами разного масштаба в моменты обострения, в том числе меры, направленные на поддержание устойчивости экономки и снижение социальной энтропии.

Ключевые слова: управление, социально-экономические системы, режимы с обострением, социальные вызовы, методология.
\end{abstract}

Благодарность. Работа выполнена при финансовой поддержке РФФИ, проект 21-01131500 .

\section{Для цитирования}

Афонасова М. А. Управление социально-экономическими системами в условиях роста неопределенности и новых социальных вызовов // Вестник Бурятского государственного университета. Экономика и менеджмент. 2021. № 4. С. 10-17.

Актуальность исследования обусловлена тем, что в настоящее время социально-экономическое развитие характеризуется неустойчивостью, несбалансированностью, невосприимчивостью к инновациям, социальной энтропией, что является важнейшей проблемой, сдерживающей экономический рост и препятствующей прогрессивному развитию страны. Глобальный финансовоэкономический кризис, пандемия коронавируса, внутренние экономические проблемы повлияли на сокращение масштабов экономической деятельности в стране, рост безработицы, снижение доходов населения, появление новых социальных вызовов. «Наша экономика не генерирует рабочие места, мы уже больше 20 лет видим отрицательное сальдо между созданными и сокращенными рабочими местами» [1].

Результаты социологического исследования, проведенного Институтом социально-политических исследований РАН, показали, что «тревожность граждан- 
M. А. Афонасова. Управление социально-экономическими системами в условиях роста неопределенности и новых социальных вызовов

ского общества в сентябре 2020 г. по поводу своего экономического положения оставалась на довольно высоком уровне. Доминирующей тревогой массового сознания являлась «дороговизна жизни» $(61 \%)$, за ней следовали «экологическая обстановка» $(39 \%)$, «безработица» (34\%), «повышение цен на продукты питания“ (32\%), «повышение тарифов на услуги ЖКХ» (31\%). Далее структура тревожности сложилась следующим образом: «разделение общества на богатых и бедных» (29\%), «произвол чиновников» $(28 \%)$, «безопасность близких» $(25 \%)$, «страх перед будущим» (19\%), «преступность» (17\%), «ухудшение положения пенсионеров в обществе“" $(16 \%) . . . ~[2]$. При этом расходы на социальную поддержку людей сокращаются: в июне 2021 г. они оказались на 26\% ниже, чем в июне 2020 г. За шесть месяцев на социальную политику бюджет потратил 3,046 триллиона рублей, что на 149 миллиардов $(4,8 \%)$ меньше, чем годом ранее [3].

В обозримой перспективе сохранятся требования социального дистанцирования и ограничение трансграничной мобильности, более широкое распространение получает удаленные формы работы, малоконтактное производство, что приведет к пересмотру сложившихся социальных ценностей, актуализируется проблема доступности удовлетворения индивидуальных потребностей как важнейшей социальной ценности. Возрастает угроза того, что пандемия приведет к «антидемократическому откату» и прогрессирующей авторитаризации власти, что может спровоцировать рост гражданской и политической активности населения. Это, в свою очередь, может повысить трансформационную нагрузку на экономику и социум, привести к обострению ситуации в стране, росту социальной энтропии и тревожности. Общество может оказаться перед выбором - сохранять существующую стагнацию с целью «просто пережить» существующий кризис или резко активизироваться и воспринимать кризис как источник новых возможностей для будущего более устойчивого развития.

Целью исследования является теоретическое обоснование концепции и механизмов управления развитием социально-экономических систем, функционирующих вбллизи моментов обострения. По мнению экспертов, неустойчивое состояние и тревожность общества чаще всего обусловлены тем, что социальноэкономические системы несвоевременно реагируют или совсем не реагируют на происходящие во внутренней и внешней среде изменения. Глобальные социальные, технологические и политические изменения, рост неустойчивости мировой экономики оказывают дестабилизирующее воздействие на способность социально-экономических систем сохранять устойчивость, способствуют возникновению режимов с обострением, характеризующихся быстрым нарастанием негативных процессов, трансформацией системы ценностей, ростом социальной энтропии.

Исследование проблемы обеспечения устойчивости и управляемости социально-экономических систем вблизи моментов обострения затрагивает решение самых острых проблем российской экономики, таких как замедление темпов экономического роста, массовое бегство капиталов из страны, негативные последствия падения курса рубля, угроза разрастания экономической рецессии, социальная энтропия и т. д.

Социально-экономическое развитие в нашей стране в последнее время осуществляется в сложных геополитических и макроэкономических условиях, что проявляется в неустойчивых режимах функционирования, появлении новых глобальных вызовов и угроз, изменении социальных практик и коммуникаций. 
С позиции принятой в проведенном исследовании методологии устойчивость представляет собой такое состояние системы, при котором она реализует необходимые для ее существования функции, сохраняя при этом свою системнофункциональную целостность при различных по направленности и интенсивности воздействиях со стороны внешней и внутренней среды [4].

Поэтому устойчивой можно назвать такую социально-экономическую систему, которая характеризуется следующими свойствами:

- ресурсном аспекте - достаточностью всех видов ресурсов для обеспечения функционирования и развития системы в соответствии со стратегическими целями и задачами социально-экономического развития;

- структурном аспекте - динамическим равновесием и внутренней согласованностью всех элементов и подсистем социально-экономической системы;

- функциональном аспекте - эффективным функционированием и развитием системы в среднесрочной и долгосрочной перспективах;

- социальном аспекте - гарантированной занятостью, лояльностью персонала, социальной стабильностью, развитой системой материального и морального стимулирования производительного труда.

Когда система под влиянием внешних или внутренних дестабилизирующих факторов выходит за границы устойчивости, она может отклониться от заданного режима функционирования, попасть в зону турбулентности и начать функционировать в режиме с обострением.

Известно, что в основе режимов с обострением лежит положительная обратная связь, которая приводит к раскачке социально-экономической системы, к ее переходу от устойчивого состояния к неустойчивому режиму функционирования. Режим с обострением, таким образом, представляет собой такой процесс быстрых изменений в социально-экономической системе, при котором отдельные параметры системы могут неконтролируемо возрастать за определенное время. Как правило, режим с обострением предваряет длительная квазистационарная фаза, когда влияние дестабилизирующих факторов на систему незначительно и она способна погасить их воздействие. Но затем, когда воздействие флуктуаций нарастает, система «перешагивает» порог медленного роста и может перейти в режим сверхбыстрого развития отдельных процессов, т. е. в режим с обострением.

Вблизи момента обострения усиливается хаотическая составляющая системы, появляется возможность роста влияния микроскопических (малозначимых) флуктуаций и их разрастания до макроскопических размеров. Последствия такого разрастания тоже макроскопические, заключающиеся в нарушении пропорций и темпов развития сложной социально-экономической системы, необходимых для поддержания ее целостности и устойчивости

В результате повышается вероятность реализации негативных сценариев развития системы, включая разрушение связей и возможный распад системы как один из сценариев прохождения системой момента обострения [5]. То есть ход социально-экономических процессов за короткое время может кардинально образом измениться, в том числе замедлиться, причем замедляются при этом и темпы развития экономики, науки, образования и т. д.

Таким образом, вблизи момента обострения может происходить как резкое ускорение темпов развития, так и их резкое замедление. Причиной этого являет- 
M. А. Афонасова. Управление социально-экономическими системами в условиях роста неопределенности и новых социальных вызовов

ся конкуренция двух групп факторов - ускорения и торможения, а также последующее доминирование одной из них, которое и обусловливает динамику развития системы. Конкуренция между двумя этими группами факторов приводит к преобладанию либо положительных, либо отрицательных обратных связей, что обусловливает разные режимы развития процессов в социально-экономической системе. С одной стороны, может установиться режим самоподстегивающего роста интенсивности и продуктивности процессов вблизи момента обострения, с другой стороны, может быть запущен процесс снижения интенсивности, темпов роста экономических процессов, роста социальной энтропии, рассеивания энергии и структур.

Таким образом, сложные социально-экономические системы в процессе своего развития пульсируют, подвергаются естественным колебаниям, в ходе которых тенденция дифференциации сменяется тенденцией интеграции, ослабление связей - их усилением, возрастание интенсивности - ее снижением [5], распад элементов - возникновением новых и их объединением. Все социальноэкономические системы вблизи моментов обострения демонстрируют внутреннюю неустойчивость, подвижность процессов, чувствительность даже к малым флуктуациям, которые могут привести к макроскопическим последствиям, включая кризисные явления, угрозу распада элементов и разрушения системы.

Динамика социально-экономических систем характеризуется определенной соразмерностью конструктивных и деструктивных процессов, которые последовательно сменяют друг друга. Однако там, где масса флуктуаций выходит за некоторую критическую черту, соразмерность нарушается, система преодолевает границы устойчивости и переходит в непредсказуемый режим функционирования [6], т. е. в режим с обострением.

Особенно актуальной проблема управления социально-экономическим развитием вблизи моментов обострения становится в периоды осуществления масштабных трансформаций, реформ, а также в условиях роста неустойчивости и непредсказуемости внешней среды, появления новых глобальных вызовов и угроз, способных оказывать долговременное влияние на развитие социальной и экономической сфер. К тому же отсутствует общепризнанная научно обоснованная концепция управления социально-экономическими системами, функционирующими вблизи моментов обострения.

С точки зрения синергетики для обеспечения устойчивости, сбалансированности экономики и ее развития в соответствии с заданными целями необходима определенная доля самоорганизации в системе в сочетании с эффективным управлением, предполагающим контроль и координацию деятельности различных элементов и подсистем. Причем обе эти составляющие должны быть сбалансированы и согласованы друг с другом.

Анализ практики управления социально-экономическим развитием в последние десятилетия показал, что отсутствие прогресса в преодолении неблагоприятных тенденций, сложившихся в российской экономике и социуме, в значительной степени обусловлено следующими причинами:

- органами государственного управления не учитывается непрерывное возникновение в социально-экономических системах малых и сверхмалых изменений (флуктуаций), которые, накапливаясь, способствуют переходу систем в неустойчивое состояние; 
- слабый учет действия положительных и отрицательных обратных связей в экономике и социуме, способствующих переходу систем в режим с обострением;

- отсутствие освоенных управленцами технологий и методов управления экономикой и социумом в периоды крайней неустойчивости, масштабных потрясений, сопровождающихся трансформацией системы ценностей, ростом социальной энтропии.

Так, социальная энтропия рассматривается здесь как проявление дезорганизации в социально-экономической системе. Энтропийный подход в настоящее время все чаще используется при анализе социальных процессов и различных сфер общественной жизни. Социальная энтропия может служить своеобразной мерой организованности или дезорганизованности в системе [7]. Считается, что чем более организованы в системе процессы и связи между ними, тем выше социальный порядок в системе и тем меньше энтропии содержится в ней, и наоборот.

Социальная энтропия проявляется через нарушение сбалансированности системы, приводит к дезорганизации, росту социального хаоса, поэтому она может служить фактором, подталкивающим систему, функционирующую в режиме с обострением, к некоторому пределу, границе устойчивости. То есть нарастание социальной энтропии может привести к росту непредсказуемости поведения социально-экономической системы, служить источником дисбалансов, особенно в условиях наличия институциональных дефектов, противоречивости ряда принимаемых решений, их несоответствия естественным тенденциям развития систем, а также отсутствия социального доверия к государству, эффективных инструментов согласования интересов различных социальных групп, трансформации системы ценностей.

В настоящее время из-за отсутствия целостной, научно обоснованной концепции управления социально-экономическими системами в периоды крайней неустойчивости, вблизи моментов с обострением процесс социальноэкономического развития в нашей стране идет сложно, противоречиво, целый ряд стратегических установок и проектов не выполняется, структурные диспропорции усиливаются, отсутствует адекватный механизм обеспечения экономического роста и устойчивости экономики. Кроме того, административные, экономические, институциональные и другие рычаги и инструменты управления не увязаны между собой, не учитывают особенности современного этапа развития, в результате чего возникают трудности в реагировании социальноэкономических систем на новые технологические и социальные вызовы и угрозы, а также риски, связанные с принципиальными изменениями, происходящими на глобальных рынках, с масштабными трансформациями и осуществляемыми реформами.

Поэтому решение проблемы обеспечения устойчивости социальноэкономического развития, управляемости систем в кризисных ситуациях, в периоды крайней нестабильности и непредсказуемости настоятельно требует научного обоснования концепции и механизмов управления социально-экономическими системами, функционирующими вблизи моментов обострения, призванных минимизировать возникающие неблагоприятные ситуации и обеспечивать их успешное разрешение путем поддержания равновесия между элементами, связями и процессами, протекающими внутри системы и во внешней среде, а также 
M. А. Афонасова. Управление социально-экономическими системами в условиях роста неопределенности и новых социальных вызовов

путем применения эффективных предупредительных мер для снижения рисков возникновения кризисных ситуаций и неблагоприятных траекторий развития систем.

Очевидно, что достижение цели обеспечения устойчивости социальноэкономического развития в периоды кризисов и масштабных потрясений невозможно без изменений в системе государственного управления, процессах, механизмах управления социально-экономическими системами. В самом общем понимании механизмы являются результатом целенаправленной деятельности людей и представляют собой определенную совокупность инструментов, условий, норм, правил, обеспечивающих достижение заданных целей [8]. В проведенном исследовании механизмы управления социально-экономической системой, функционирующей вблизи моментов обострения, мы определяем как упорядоченную совокупность инструментов, институциональных установок и условий, обеспечивающих поддержание динамического равновесия между элементами, связями и процессами, протекающими внутри системы и во внешней среде.

Элементами такого механизма являются совокупность необходимых ресурсов и способы их распределения; институциональные установки, мотивирующие экономических субъектов действовать в соответствии с необходимыми для обеспечения устойчивости системы приоритетами; инструменты адаптации системы к происходящим изменениям; превентивные меры по поддержанию устойчивости системы в условиях происходящих изменений, включающие способы, рычаги и технологии поддержания устойчивости экономической и социальной сфер вблизи моментов обострения.

С точки зрения методологии, используемой в исследовании, механизмы управления социально-экономическими системами вблизи моментов обострения можно разделить на два больших блока: организационные и самоорганизационные.

Организационные механизмы представляют собой совокупность инструментов и методов, необходимых для «жесткого» регулирования системы, переходящей в режим с обострением или находящейся вблизи момента обострения, с целью удержания ее от непредсказуемого поведения и нежелательного варианта развития событий. Примерами организационных механизмов могут служить распорядительные, законодательно-нормативные, экономические и др. механизмы.

Самоорганизационные механизмы необходимы любой сложноорганизованной системе для ее адаптации, т. е. своевременной реакции на изменения, происходящие во внешней среде. Фактически они представляют собой механизмы самоупорядочивания, самомотивации системы, основанные не на принципах иерархии, а на горизонтальных коммуникациях. Под самоорганизацией принято понимать процесс установления в системе порядка без внешних упорядочивающих воздействий, т. е. без вмешательства органов управления [9]. Для обеспечения устойчивости системы вблизи момента обострения количество ее внутренних реакций должно соответствовать количеству внешних импульсов со стороны внешней среды. Самоорганизующаяся система выстраивает такую неформальную структуру, в которой каждому внешнему воздействию соответствует элемент, способный генерировать эффективные ответные реакции на внешние воздействия и влиять на функциональное разнообразие системы [10]. 
Таким образом, анализ перспектив обеспечения динамической устойчивости и управляемости социально-экономических систем, функционирующих вблизи моментов обострения, позволил вскрыть природу неустойчивости в результате происходящих глобальных изменений, раскрыть сущность режимов с обострением, обусловленную действием положительных обратных связей, предложить новую методологическую версию решения проблемы управления устойчивостью и социальной стабильностью общества в периоды масштабных трансформаций, кризисов, связанных с новыми глобальными технологическими, экономическими и социальными вызовами.

\section{Литература}

1. Афонасова М. А. К вопросу об устойчивости экономических систем в условиях неопределенной внешней среды // Вестник Алтайской академии экономики и права. 2020. № 2. C. 20-27. URL: https://www.vaael.ru/ru/article/view?id=994 (дата обращения: 10.08.2021). Текст: электронный.

2. Афонасова М. А. Самоорганизация социально-экономических систем: монография. Томск: Изд-во Томск. гос. ун-та систем управления и радиоэлекторники, 2004. 138 с. Текст: непосредственный.

3. Жигалова В.Н.Повышение потенциала экономической устойчивости предприятия: диссертация на соискание ученой степени кандидата экономических наук: 08.00.05. Барнаул, 2007. 22 с. Текст: непосредственный.

4. Князева Е. Н., Курдюмов С. П. Синергетика: нелинейность времени и масштабы коэволюции: монография. Москва: КомКнига, 2011. 272 c. URL: https://elibrary.ru/ item.asp?id=23690244 (дата обращения: 10.08.2021). Текст: электронный.

5. Николис Г., Пригожин И. Самоорганизация в неравновесных системах. От диссипативных структур к упорядоченности через флуктуации. Москва, 1979. 399 с. Текст: непосредственный.

6. Прокофьев А. Безработица и коронавирус: что происходит на рынке труда. URL: https: // polit.ru/article/2020/05/06/ coronaworkfail/utm_source=yxnews\&utm_ medium=desktop\&utm_referrer $=$ https\%3A\%2F\%2Fyandex.ru\%2Fnews (дата обращения: 10.08.2021). Текст: электронный.

7. Прокофьев Д. А. Бедные и послушные // Новая газета. 2021. № 80. 23 июля. URL: https://novayagazeta.ru/articles/2021/07/21/bednye-i-poslushnye (дата обращения: 10.08.2021). Текст: электронный.

8. Социальное государство и гражданское общество в условиях реализации национальных проектов: монография / В. К. Левашов, Н. М. Великая, И. С. Шушпанова [и др.] / отв. ред. В. К. Левашов; ФНИСЦ РАН. Москва: ФНИСЦ РАН, 2021. 128 с. URL: https://www.fnisc.ru/index.php?page_id=1198\&id=9514 (дата обращения: 10.08.2021). Текст: электронный.

9. Тетерина Е. В. Энтропийные процессы в социальной сфере // Вестник КРАСГАУ. 2013. № 11(86). С. 297-299. Текст: непосредственный.

10. Толочко А. В. Влияние региональной экономической безопасности на устойчивое и безопасное развитие страны / А. В. Толочко // Инновационное развитие экономики. 2020. № 4-5(57-58). С. 307-312. URL: http://dlib.rsl.ru (дата обращения: 10.08.2021). Текст: электронный.

Статья поступила в редакцию 19.08.2021; одобрена после рецензирования 29.10.2021; принята к публикации 01.11.2021. 


\title{
MANAGEMENT OF SOCIO-ECONOMIC SYSTEMS IN THE CONDITIONS OF GROWING UNCERTAINTY AND NEW SOCIAL CHALLENGES
}

\author{
Margarita A. Afonasova \\ Dr. Sci. (Econ.), Prof., \\ Tomsk State University of Control Systems and Radio Electronics \\ 40 Lenina Prospect, Tomsk 634050, Russia \\ afonasova@yandex.ru
}

Abstract. The article considers the methodological aspects of managing socio-economic systems during periods of large-scale changes and transformations caused by new technological, economic and social challenges. The relevance of the study is conditioned by the lack of a generally accepted scientific-based methodology for state management of socio-economic systems functioning in regimes with exacerbation, which have been provoked by new challenges and threats, the growth of instability and unpredictability of the external environment. The article reveals the features of functioning systems in a regime with exacerbation and the course of control actions on such systems at the moments of exacerbation. We have discussed the mechanisms of managing various socio-economic systems in the periods of exacerbation, including measures aimed at maintaining the stability of the economy and reducing social entropy.

Keywords: management, socio-economic systems, regimes with exacerbation, social challenges, methodology.

Acknowledgments: The work was supported by the RFBR grant 21-011-31500.

\section{For citation}

Afonasova M. A. Management of Socio-Economic Systems in the Conditions of Growing Uncertainty and New Social Challenges. Bulletin of Buryat State University. Economy and Management. 2021; 4: 10-17 (In Russ.).

The article was submitted 19.08.2021; approved after reviewing 29.10.2021; accepted for publication 01.11.2021. 